\title{
Lightning Injury: Two Case Histories and a Review of Management
}

\author{
GILLIAN C. HANSON, G. R. MCILWRAITH
}

British Medical fournal, 1973, 4, 271-274

\begin{abstract}
Summary
Two cases of fatal lightning injury are described. Fixed dilated pupils shoukd not be taken as an indicator of death after a lightning strike. Persons who fail to breath spontaneously within one minute of lightning shock should receive external cardiac massage and mouth-to-mouth resuscitation. Paralysis may persist as result of cerebral oedema or prolonged hypoxia-it is therefore suggested that adequate ventilation and metabolic balance should be maintained until recovery or death.
\end{abstract}

\section{Introduction}

Two brothers, aged 9 and 15, were admitted to the Aocident Centre at Whipps Cross Hospital, at 5.15 p.m. one evening in July 1972.

The children were sheltering with five other boys in a tent which was adjacent to the dining shelter where an adult was stationed with the tent flap open in order to observe what was happening. It was raining heavily and there was a severe thunderstorm.

At about 4.45 p.m. there was a sudden flash of lightning which struck the tent pole and enveloped the whole tent. Almost immediately screams were heard from within the tent. The adult found several children stunned but breathing adequately. Two children were unconscious and not breathing. Both received mouth-to-mouth ventilation and external cardiac massage within three minutes of the incident. The ambulance arrived about 10 minutes later and oxygen was given to the older child. At 5 p.m. they were placed in the ambulance and given external cardiac massage and mouthto-mouth ventilation until they arrived at the hospital 15 minutes later.

\section{Case 1}

On arrival in casualty the 9-year-old boy was apnoeic and cyanosed, the femoral pulse was impalpable, and heart sounds were absent. The pupils were widely dilated and unresponsive to light; there were no fundal abnormalities. The child was intubated and hand ventilated with oxygen. (Vomitus was aspirated from the lungs at the time of intubation.) The cardiogram showed asystole. An infusion of $200 \mathrm{ml} 4 \cdot 2^{\circ}$, sodium bicarbonate was given over 10 minutes, followed by an injection of $10 \mathrm{ml} 10 \%$ calcium gluconate, both intravenously. An intracardiac injection of $2 \mathrm{ml}$ of $1: 1,000$ adrenaline produced ventricular fibrillation; this was converted to sinus rhythm by D.C. cardioversion. The femoral pulse became palable within a few minutes; the brachial blood pressure remained unrecordable. Spontaneous respiration returned, but as this was in-

Intensive Therapy Unit, Whipps Cross Hospital, London E11 1NR GILLIAN C. HANSON, M.B., M.R.c.P., Consultant Physician

GEORGE R. MCILWRAITH, M.B., M.R.C.P., Medical Registrar, and Research Fellow and Honorary Senior Registrar at King's College Hospital, London S.E.5 adequate hand ventilation was continued. He was transferred to the intensive therapy unit.

On admission the skin was cold, pale, and clammy; there was severe peripheral cyanosis, the pupils remained fixed and dilated, and there was no response to skin stimulation. The rectal temperature was $28.5^{\circ} \mathrm{C}$, the skin temperature $26.0^{\circ} \mathrm{C}$. There was singeing of the hair in the left temporal region and flash singeing of the right brow and temple. There were flash burns over the left side of the face (fig. 1), over the front of the chest, and down the right flank, with patches around the right ankle. There were current exit sites on both little toes. The E.C.G. showed sinus rhythm at $140 / \mathrm{min}$ with S-T elevation in leads II, III, AVF, and V6 (fig. 2). A rapid infusion of $200 \mathrm{ml}$ dextran 70 was given by which time a central venous pressure line had been inserted and registered $8 \mathrm{~cm}$ water in the mid thoracic plane. The patient was given $100 \%$ oxygen with an Engstrom ventilator. Blood taken after the infusion of sodium bicarbonate and $15 \mathrm{~min}$ after admission showed an Astrup analysis of $\mathrm{pH} 6.93, \mathrm{PaCO}_{2} 70 \mathrm{~mm} \mathrm{Hg}$, base excess 20 $\mathrm{mEq} / \mathrm{l}$., standard bicarbonate 10.5 , and $\mathrm{PaO} .>220 \mathrm{~mm} \mathrm{Hg}$. The electrolytes were within normal limits, $\mathrm{Hb} 11.8 \mathrm{~g} / 100 \mathrm{ml}$, packed cell volume $37 \%$. A further $200 \mathrm{ml} 4.2 \%$ sodium bicarbonate was infused, followed by $100 \mathrm{ml} 10^{\circ}$ mannitol.

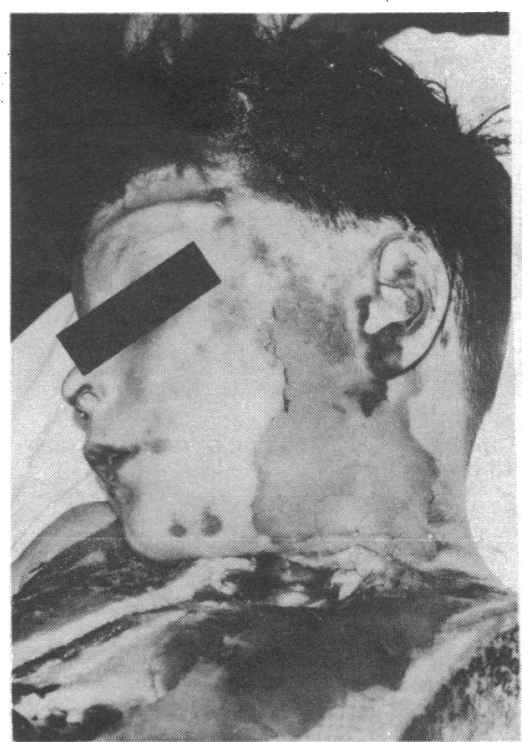

FIG. 1-Case 1. Flash burns over left side of face.

About an hour after admission the rectal temperature had risen to $30^{\circ} \mathrm{C}$ and the skin temperature to $27^{\circ} \mathrm{C}$. The skin remained blue and mottled, the $\mathrm{pH}$ had risen to 7.37, and the base excess was within normal limits. At this time severe gastrointestinal dilatation was noted; gastric aspirate was about $100 \mathrm{ml}$ hourly. The central venous pressure fell to $3 \mathrm{~cm} \mathrm{H}_{2} \mathrm{O}$ and was restored to normal levels with $1,000 \mathrm{ml}$ of dextrose/saline $(4 \cdot 3 \% / 0 \cdot 18 \%)$. The urine output was less than $40 \mathrm{ml} / \mathrm{hr}$.

The patient's shocked condition remained critical, and during the night he sustained two asystolic arrests. Resuscitation was abandoned 12 hours after admission.

Necropsy showed an aspiration pneumonia. There was a circumscribed area of dead tissue on the posterior aspect of the left 

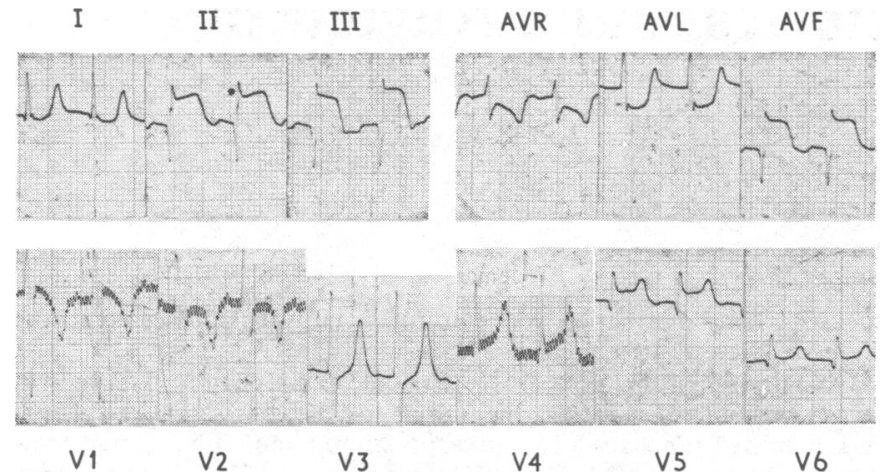

FIG. 2-Case 1. E.C.G. changes at time of admission.

ventricle. Histology showed coagulative necrosis of the muscle fibres consistent with a blast injury. The histological appearances were unlike those of myocardial contusion secondary to external cardiac massage. The bowel and stomach were grossly dilated; the stomach contained multiple erosions, and the ascending colon was severely bruised (fig. 3). There was no perforation.

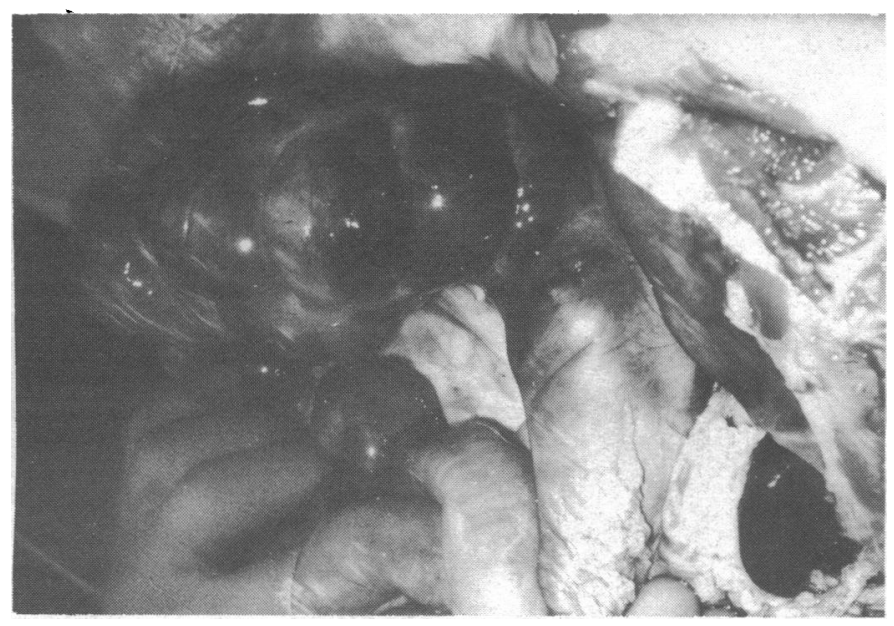

FIG. 3-Case 1. Appearances of ascending colon at necropsy. Severe bruising presumably due to blast injury.

\section{Case 2}

The 15-year-old brother was on admission unresponsive to all stimuli, deeply cyanosed, with fully dilated, non-reacting pupils, apnoeic, and pulseless. He was intubated and hand ventilated with oxygen. External cardiac massage was continued. His cardiogram showed fine ventricular fibrillation which, after an intracardiac injection of $1 \mathrm{ml}$ of $1: 1,000$ adrenaline, converted to ventricular tachycardia and then sinus rhythm. He was given an infusion of $200 \mathrm{ml} 4.2 \%$ sodium bicarbonate and transferred to the intensive therapy unit.

On arrival the skin was cold and pale but not cyanosed, the pulse volume was good, and the systolic blood pressune recordable at $80 \mathrm{~mm} \mathrm{Hg}$. The rectal temperature was $38^{\circ} \mathrm{C}$, skin temperature $24^{\circ} \mathrm{C}$. The E.C.G. showed S-T elevation associated with $\mathrm{Q}$ waves in leads II, III, AVF, and V6 (fig. 4). A $1,000-\mathrm{ml}$ infusion of dextran 70 was followed by $200 \mathrm{ml} 10 \%$ mannitol. Since there was no spontaneous ventilation a ventilator was used. Flash burns were visible over the centre brow, left temple, bridge of the nose, and cheeks. Current exit sites were visible on the outer bonder of both little toes.

Four hours after admission the abdomen became grossly distended, gastric aspirate increased, the pulse and blood pressure became unrecordable, and the central venous pressure registered

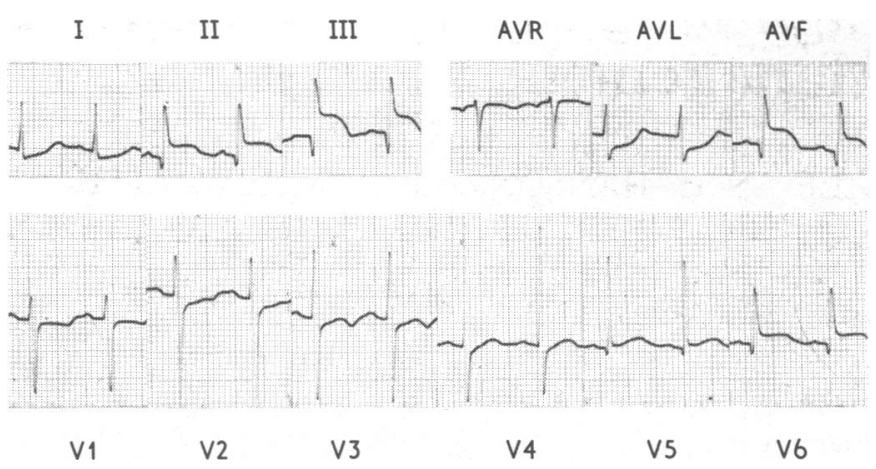

FIG. 4-Case 2. E.C.G. changes at time of admission.

$1.5 \mathrm{~cm} \mathrm{H}_{2} \mathrm{O}$. A rapid infusion $1,000 \mathrm{ml}$ normal saline was followed by $250 \mathrm{ml}$ dextran 70 . After one hour the central venous pressure registered $8 \mathrm{~cm}$ water. In spite of a good femoral pulse no blood pressure was recordable; urine output was adequate.

The next day the patient's condition had improved-skin perfusion was good and urine output was normal. The pupils remained fixed and dilated. Twelve hours after admission he developed signs suggestive of intermittent sympathetic overactivity-namely, a fluotuating sinus tachycardia and a blood pressure varying between $180 / 120$ and $200 / 140 \mathrm{~mm} \mathrm{Hg}$. At these times the extremities were cyanosed and cold with a normal or raised rectal temperature. The tachycardia was controlled with a practolol infusion. These signs gradually subsided, and the dosage of practolol was slowly tailed off and stopped seven days after his admission.

Two days after admission increased airway resistance developed due to increasing bronchospasm. The lung aspirate during this period was haemorrhagic. The patient was started on intramuscular prednisolone phosphate $10 \mathrm{mg}$ six hourly which resulted in a diminution of the airway pressure. This was reduced to $5 \mathrm{mg} \mathrm{12-hourly}$ by the eighth day, by which time there was little bronchospasm and airway pressures (as recorded on the ventilator) were within normal limits.

The abdominal distension had decreased by the third day and oral feeding became possible. The E.C.G. at this time showed decreasing S-T elevation in leads II, III, and AVF (fig. 5). On the fourth day the patient made attempts at spontaneous ventilation but on no occasion could it be maintained. His pupils remained fixed and dilated, and an E.E.G. taken on the fifth day after admission showed no cerebral activity.

By the sixth day his general condition began to deteriorate. There was a steady fall in rectal temperature in spite of attempts at rewarming, the pulse became slow, and the skin mottled. He developed an asystolic arrest on the nineth day of admission.

At necropsy the brain showed colliquative softening with swelling and herniation of the brain stem.

The heart muscle was pale and a haemorrhagic patch was visible in the middle of the posterior wall of the left ventricle. Neither the lungs nor the intestine showed any bruising.
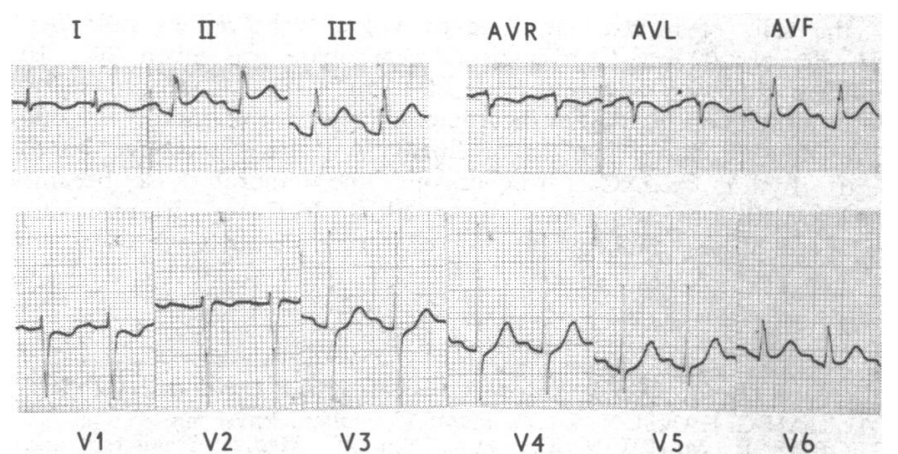

FIG. 5-Case 2. E.C.G. changes three days after injury. 


\section{Comments}

Both cases showed remarkable similarities.

Apparently, the younger child had wet clothes and was leaning again the tent pole when the lightning struck. The position of the elder child was not known. The direct effect of the current passing through or near the surface of the body in the younger child was seen by charring and necrosis of the skin over the left side of the face, over the chest, and down the right flank. In both boys the sites of exit of the current were through the soles of the feet. In addition to burns there may be visible abrasive markings on the skin surface (Jellinek, 1928).

Both boys seemed dead when first seen in hospital. It is remarkable that the myocardium was capaable of normal rhythm after such a prolonged period of hypoxia. Both children were cold on admission, and this had undoubtedly reduced the metabolic oxygen demand. It is possible that both might have survived if they had reached hospital earlier. The younger boy did not receive oxygen in the ambulance and the extensive pulmonary aspiration at the time of the injury contributed to the severity of the hypoxia.

Both children developed acute gastrointestinal dilatationassociated with hypovolaemia and shock.

The elder child suffered contusion on the lateral aspect of the left lung, whereas the younger child showed severe contusion of the ascending colon at necropsy. It is probablc that these injuries were secondary to the lightning shock.

Both children developed similar E.C.G. changes consistent with severe myocardial damage of the posterior aspect of the left ventricle. At necropsy a well defined haemorrhagic area was visible which on microscopical examination in the younger child showed histological changes consistent with a blast injury. Detailed histological examination of the affected area was not performed in the older child.

The burns were superficial and would have healed spontaneously.

\section{Management}

If a group of people are struck by lightning some may be stunned but continue spontaneous ventilation and a few may fall unconscious, become pulseless, and stop breathing. Generally the apnoea and cardiac arrest is temporary. Persons who are apnoeic should not be taken as dead, but mouthto-mouth resuscitation and external cardiac massage should be instituted immediately. Patients who have sustained severe lightning injury appear to withstand prolonged periods of apnoea (Ravitch et al., 1961; Nesmith, 1971). Taussig (1968) postulated that after lightning strike the cessation of metabolism in all cells is so instantaneous that the onset of degenerative processes is delayed.

On arrival at hospital full resuscitation should be instituted. The patient should be intubated and ventilated and the cardiac activity assessed. Cardiac asystole is regarded as a sequel of severe irritation of the vagus nerve (Lynch and Shorthouse, 1949.) Intracardiac adrenaline is likely to stimulate cardiac pulsation. This should be supplemented with an infusion of isoprenaline if the E.C.G. shows sinus bradycardia. Intracardiac adrenaline may precipitate ventricular fibrillation, which can then be treated by D.C. shock.

Lack of spontaneous ventilation and fixed dilated pupils do not necessarily portray a bad prognosis. A ventilator should be used and the blood gases maintained within normal limits. Bilateral blindness associated with optic atrophy has been reported, and this may on occasions account for nonreacting pupils in patients suffering from lightning shock (Taussig, 1968).

Insertion of a central venous pressure line is essential in lightning injury in order to assess the dynamic blood volume and right ventricular tolerance. Rapid gastrointestinal dila- tation may lead to acute hypovolaemia and electrolyte imbalance. A metabolic acidosis secondary to poor peripheral perfusion should be corrected to a base deficit of 10 . Initial correction to a normal value may lead to over-correction as peripheral perfusion imoroves or lead to cardiac failure secondary to sodium overload.

The rectal temperature should be maintained at around $33-37^{\circ} \mathrm{C}$. Patients with cerebral oedema tend to become hyperpyrexial, and cooling may be necessary.

The significance of cerebral oedema after electrotrauma has been emphasized by Jellinek (1928). His findings suggested that this can develop rapidly. Restoration of respiration may be impaired by the increase in cerebrospinal fluid pressure due to cerebral oedema. Mannitol should be infused at the time of resuscitation and a short course of dexamethasone prescribed if the patient remains comatose after half an hour of adequate resuscitation. The dexamethasone should be stopped as soon as there is improvement in the level of consciousness.

A patient who develops cerebral oedema is best managed initially by means of a ventilator since the blood gases can be kept within normal limits, the metabolic demands of the patient are reduced, body cooling is easier, and any seizures can be easily controlled by sedation without fear of respiratory depression.

Gastrointestinal dilation was very striking in our two patients and this increases the risk of pulmonary aspiration. Early stomach aspiration and continuous drainage is mandatory.

When a discharge of enormous potential takes place the expanded, displaced, and returning air may cause blast-like lesions. These lesions may manifest as lung contusion, intestinal contusion, and as subarachnoid or cerebral haemorrhage (Spaar, 1954; Peters, 1956). Lung contusion may be an indication for intermittent positive-pressure ventilation, the lesion producing a shunt effect with a fall in $\mathrm{PaO}_{2}$ and tachypnoea.

Bowel contusion may be associated with intestinal ileus and on occasions intestinal bleeding.

The myocardium may be affected in lightning injury, a blast injury may lead to myocardial contusion, or a primary electrical injury may produce muscle fibre necrosis. The E.C.G. picture is generally that of an infarct pattern and may be sited on the anterior or inferior aspects of the left ventricle. These E.C.G. changes have been reported in patients who have not received cardiac massage (Burda, 1966; K.leinot et al., 1966.) The E.C.G. abnormalities may take months to resolve. Burda (1966) suggested that true vascular occlusion may be precipitated by the extreme stress associated with lightning shock in patients with coronary artery disease. The E.C.G. changes in the younger boy were found to be due to contusion of the myocardium secondary to the lightning shock. There was no evidence of any coronary artery occlusion. The E.C.G. changes, which were similar in the older boy, had improved dramatically by the third day (fig. 5). The older boy showed a raised SGOT level, reported previously (Keinot et al., 1966).

The myocardial change may be associated with cardiac dysrhythmias and should be appropriately treated.

It is noteworthy that the older child had clinical signs consistent with intermittent catecholamine release. Catecholamines assayed on day 3 showed a raised level of total venous catecholamines - the dominant amine being adrenaline. It is probable that the stress of severe lightning injury may be associated with catecholamine release. Assay of these amines is indicated whenever there is evidence of tachvcardia, hvpertension, excessive sweating, fluotuating pyrexia, or cold, cyanosed extremities. In such instances an intravenous test dose of a $\beta$-adrenergic blocking agent should be given. A fall in pulse rate may be an indication for a continuous infusion of practolol. 
The decision when to abandon treatment is difficult.

At the initial phase of resuscitation normal tests for death should not be accepted. However, refractory asystolic arrest and a rapid fall in body temperature unresponsive to rewarming are reasonable criteria of death.

\section{Conclusion}

Any person who receives a lightning injury and does not regain consciousness within one minute should receive external cardiac mssage and mouth-to-mouth resuscitation until ventilation and peripheral perfusion is adequate. At the time of lightning shock generalized paralysis may develop which generally disappears after a few minutes, and complete restoration seldom requires more than 24 hours (Dannhorn, 1937). Occasionally paralysis may persist as a result of cerebral oedema or a prolonged period of hypoxia (Morikawa and Steichen, 1960).

Fixed dilated pupils are well recognized after lightning stroke and should not be used as an indicator of cerebral death. E.E.G. records have not been taken from many patients with lightning strike (Gathier, 1960) and therefore should be interpreted in association with the clinical findings.
In the light of present medical experience we feel it reasonable to ensure adequate ventilation and maintain metabolic and fluid balance until recovery or death.

We are indebted to Professor K. Simpson for his help in the photography and for providing the necropsy reports. We are also grateful to Dr. C. Raeburn, consultant pathologist at Whipps Cross Hospital, for the histological reports.

\section{References}

Burda, C. D. (1966). American Heart fournal, 72, 521.

Dannhorn, G. (1937). Veroffentliche Gebiete des Volksgesundheitsdienstes, vol. 48, pt. 7. Berlin, Schetz.

Cathier, J. C. (1960). Psychiatrica, Neurologia, Neurochirurgia, 63, 125.

Jellinek, S. (1928). Weiner klinische Wochenschrift, 41, 622.

Kleinot, S., Klachko, D. M., and Keeley, K. J. (1966). South African Medical fournal, 40, 1141 .

Lynch, M. J. G., and Shorthouse, P. H. (1949). Lancet, 256, 473.

Morikawa, S., and Steichen, F. (1960). Anesthesiology, 21, 223.

Nesmith M. A., iun. (1971). Fournal of the Florida Medical Association, 58, 36. Peters, G. (1956). Deutsche Zeitschrift fur die gesamte gerichtliche Medizin, 44,743 .

Ravitch, M. M., Lane, R., Safar, P., Steichen, F. M., and Knowles, P. (1961). New England fournal of Medicine, 264, 36

Spaar, W. (1954). Archiv fur pathologische Anatomie, 326, 732.

Taussig, H. B. (1968). Annals of Internal Medicine, 68, 1345.

\section{PRELIMINARY COMMUNICATIONS}

\section{Cell-mediated Immune Response in Primary Biliary Cirrhosis to a Protein Fraction from Human Bile}

\author{
A. L. W. F. EDDLESTON, I. G. McFARLANE, \\ C. G. MITCHELL, W. D. REED, ROGER WILLIAMS
}

British Medical fournal, 1973, 4, 274-276

\section{Summary}

Cell-mediated immune responses to a protein fraction of human bile have been demonstrated, using the leucocyte migration test, in eight out of 10 patients with primary biliary cirrhosis but in only three out of nine with active chronic hepatitis. In the latter condition sensitization to a liver-specific hepatocellular antigen was found more frequently (five out of nine patients) than in primary biliary cirrhosis (two out of 10). These results, as well as the granuloma formation observed histologically, suggest that the initial bile duct lesion in primary biliary cirrhosis may be associated with a cellmediated response to antigens-perhaps derived from bile duct epithelial cells-which may be normal constituents of hepatic bile.

\footnotetext{
Liver Unit, King's College Hospital and Medical School, London SE5 8RX

A. L. W. F. EDDLESTON, D.M., M.R.C.P., Senior Lecturer in Medicine I. G. MCFARLANE, B.SC., PH.D., Research Biochemist C. G. MITCHELL, B.SC., PH.D., Research Immunologist C. G. MITCHELL, B.SC., PH.D., Research Imm ROGER WILLIAMS, M.D., F.R.C.P., Director and Consultant Physician
}

\section{Introduction}

Little is known about the pathogenesis of primary biliary cirrhosis, though because of the presence of autoantibodies in the serum it is often thought to be autoimmune. In previous studies we have found evidence of cell-mediated immunity to a liver-specific lipoprotein both in this condition and in active chronic hepatitis which may also be due to an autoimmune reaction (Miller et al., 1972). Immunofluorescent studies have shown that this lipoprotein is a normal constituent of the hepatocyte cell membrane (Hopf et al., 1973), and sensitization to it could be of importance in the production of hefatocyte damage, which, though more characteristic of active chronic hepatitis, is also present to a varying degree in primary biliary cirrhosis. The earliest lesions in primary biliary cirrhosis involve the interlobular bile ducts (Scheuer, 1968) and could result from a reaction directed against bile duct antigens. This has proved difficult to demonstrate, mainly because of the technical problems involved with obtaining in man bile duct cells separate from hepatocytes. The possibility that lining mucosal cells could be shed into the lumen with release of antigenic material prompted the present study in which human bile was examined for an immunologically active protein fraction. The leucocyte migration test was used to detect cell-mediated immune responses to this bile protein fraction in patients with classical features of either primary biliary cirrhosis or active chronic hepatitis and in nine healthy volunteers. The results have been compared with those obtained in the same subjects when using the hepatocyte lipoprotein as antigen.

\section{Methods}

Preparation of Bile Antigen.-Hepatic bile was collected by $T$-tube drainage from two patients during the first 24 hours after a cholecystectomy for cholelithiasis. Each bile sample was dialysed for three days against phosphate-buffered saline, $\mathrm{pH} 7 \cdot 2$, and the proteins were precipitated with ammonium 